\title{
Targeted treatment for chronic lymphocytic leukemia
}

This article was published in the following Dove Press journal:

OncoTargets and Therapy

3 November 2011

Number of times this article has been viewed

\begin{abstract}
Aisha Masood'
Taimur Sher ${ }^{2}$

Aneel Paulus ${ }^{2}$

Kena C Miller ${ }^{2}$

Kasyapa S Chitta ${ }^{3}$

Asher Chanan-Khan ${ }^{4}$

'The Tisch Cancer Institute, Bone Marrow Transplant Unit, Mount Sinai School of Medicine, ${ }^{2}$ Department of Medicine, Roswell Park

Cancer Institute, ${ }^{3}$ Department of Molecular Targets and Experimental Therapeutics, Roswell Park Cancer Institute, New York, NY, ${ }^{4}$ Division of Hematology/Oncology, Mayo Clinic, Jacksonville, FL, USA
\end{abstract}

Correspondence: Asher Chanan-Khan Division of Hematology/Oncology, Mayo Clinic, Jacksonville, FL 32224, USA

Tel +l 904953729

Fax + I 904953231

Email asherchanankhan@me.com
Abstract: The treatment of chronic lymphocytic leukemia (CLL) has evolved over the last few decades. Recognition has increased of several key components of CLL biology currently manipulated for therapeutics. A milestone in the treatment of CLL was reached with the incorporation of immunotherapy with conventional chemotherapy. The fludarabine/ cyclophosphamide/rituximab combination has demonstrated survival advantage for the first time in the treatment of CLL. Several other biological compounds are being explored with the hope of improving responses, impacting survival, and ultimately curing CLL. Important agents being tested are targeted on CLL surface molecules and their ligands, signal transduction protein and oncogenes. This review provides a brief summary of the recent advances made in preclinical and clinical investigation of selected promising therapeutic agents, which lead the target-directed therapeutic approach.

Keywords: CLL, Akt inhibitors, Bcl-2 inhibitors, cyclin d kinase inhibitors, heat shock protein inhibitors, immunomodulatory drugs, monoclonal antibodies

\section{Introduction}

Chronic lymphocytic leukemia (CLL) is one of the most common forms of leukemia in the Western hemisphere with an annual incidence of 5.17 per 100,000 personyears. ${ }^{1}$ CLL is a heterogeneous disease carrying a variable clinical course among patients; some are monitored without any treatment, while others develop symptoms and require therapeutic intervention. ${ }^{2}$ Historically, treatment options for patients with CLL include either a nucleoside analog (fludarabine) or an alkylating agent (chlorambucil). This approach has now been surpassed by the combination regimens such as fludarabine and cyclophosphamide (FC), or more recently by the addition of rituximab to FC (FCR). ${ }^{3,4}$ Such a chemo-immunotherapy approach has significantly improved response rates as well as progression-free and overall survival..$^{5}$ Additionally newer chemotherapeutics such as bendamustine have also become available with successful clinical outcomes. Unfortunately all patients eventually relapse and CLL remains an incurable cancer. However, the dilemma continues for relapse and refractory disease, calling for insight into disease biology and development of new treatments for improved clinical outcome.

\section{Biology of CLL cells}

CLL cells are mature B-cells that express CD5, CD19, and CD23 with low levels of immunoglobulins (IgM, IgD) on the cell surface. ${ }^{6}$ These malignant cells are mostly 
arrested in the G0 phase of the cell cycle and are marked by significant deregulation of apoptosis. ${ }^{7}$ CLL cells proliferate in the lymphoid tissues and bone marrow whereas in the blood they stay dormant. ${ }^{8}$ Clonal proliferation of the malignant B cell clone also induces cellular immune defects including altered $\mathrm{CD} 4 / \mathrm{CD} 8$ ratio of $\mathrm{T}$ effector cells, functional deficiency of CD40 ligand, and an increase in the number of immune inhibitory $\mathrm{T}$ regulatory cells. Animal models infused with CLL leukemic cells have also demonstrated similar T cell defects. ${ }^{9}$ The transgenic mouse models of CLL demonstrated acquisition of changes in multiple T-cell pathways regulating antigen recognition and effector function with a reversible immunological synapse dysfunction. The majority of altered genes in the CD4 T cells are involved in cell proliferation, differentiation, and cytokine/chemokine response pathways. The B-cell receptor (BCR) plays a significant role in disease biology by engaging costimulatory molecules, protein tyrosine kinases, as well as the zeta associated protein-70 which activates signaling pathways such as p38, c-jun $\mathrm{N}$ terminal kinase, extracellular-regulated kinase, and the phosphoinositide 3-OH kinase (PI3K/ $\mathrm{PKC} / \mathrm{AKT}) .{ }^{10}$ The signal transduction pathways such as the vascular endothelial growth factor (VEGF) mediated CD40-CD40L and/or signal transducer and activator of transcription 3 interacts with the prosurvival cytokines from the microenvironment to promote leukemic cell proliferation. ${ }^{11,12}$ Interaction of the CLL cell with components of the microenvironment as well as the inherent biological characteristics of the leukemic clone induces upregulation of antiapoptotic proteins that provides additional support to the survival of the CLL cell. ${ }^{13}$ Additionally, specific genetic lesion(s) such as trisomy 12 (associated with p27, CDK4, and Bax overexpression); del(13q) (causing increased levels of protein kinase B Akt); and the del(11q) results in decreased synthesis of ataxia telengiectasia mutated (ATM) and del(17p) results in $\mathrm{p} 53$ dysfunction. The ultimate result is activation of molecular pathways responsible for CLL cell survival and drug resistance. ${ }^{12}$ Identifying these molecular markers has elucidated the development of new treatment modalities, some of which are discussed here.

\section{Application of disease biology in therapeutics}

Improved understanding of the biological processes involved in CLL through specific cell surface molecules and their ligands or downstream molecular events mediated through signal transduction proteins has enabled development of new targeted therapeutics. These newer agents can potentially suppress and disrupt the signaling cascade(s) either through interacting with the tumor cell surface, intracellular proteins or organelles, or interruption of translational events directed by tumor specific oncogenes.

In CLL, target directed therapeutic strategies incorporate maneuvers to manipulate the components of the tumor microenvironment, engagement of cell surface molecules (such as CD19, CD20, CD25, CD52, CD40, and TRAIL), or interruption of intracellular processes (such as those mediated through the Bcl-2 family of proteins, Akt, proteosome, or the heat shock proteins). ${ }^{14-16}$

\section{Targeting the microenvironment Immunomodulatory drugs}

Deregulation of the host immune response is an important step in cancer progression. Ongoing research has revealed that this deregulation of the host immune response is a multistep process that includes failure of tumor cells to express immune activating antigens, downregulation of major histocompatibility complex, and/or failure to express costimulatory ligands that normally engage corresponding receptors on $\mathrm{T}$ cells for a host-directed immune response. ${ }^{17}$ Tumor cells adulterate the microenvironment through manipulation of host cells in aberrant production of prosurvival cytokines, which either directly promote growth of the leukemic cell via activation of specific signaling pathways or induce an immune suppressive milieu fostering unchecked CLL cell proliferation. ${ }^{13,18,19}$ It has been demonstrated that interaction between tumor cells in the lymph nodes and microenvironment results in upregulation of BCR-regulated genes resulting in NFKB activation. ${ }^{20}$ The net effect is a persistent and uninterrupted growth of malignant CLL clone with progressive decline in immune surveillance.

\section{Mechanism of action}

Thalidomide and lenalidomide are a newer class of anticancer agents that belong to the group of immunomodulatory drugs (IMiDs). This group of drugs has the ability to manipulate components of the tumor-supporting microenvironment. ${ }^{21}$ They uniquely affect multiple targets within the malignant microenvironment thus altering the endogenous support mechanism of the malignant clone. Both thalidomide and lenalidomide were shown to downregulate critical prosurvival cytokines such as the VEGF, interleukin (IL)-6, tumor necrosis factor (TNF) $\alpha$, and platelet-derived growth factor that are involved in CLL cell proliferation and survival. ${ }^{22}$ Furthermore, they can also alter the leukemic cell phenotype by modulating the expression of surface antigens (such as 
CD80, CD86, and CD40), thereby contributing to improved immune directed tumor cell killing. ${ }^{19,22}$ Recently, IMiDs have also been reported to enhance T and NK (natural killer) cell recognition of CLL cells thereby directing killing of the leukemic cell. ${ }^{23}$ Collectively these observations demonstrate that IMiDs treatment is focused on modulating the elements of the tumor microenvironment and at the same time modulating surface antigen (upregulation of CD80, CD86, and CD40) of the leukemic cells resulting in the reduction of tumor burden.

Thalidomide was first investigated in combination with fludarabine in patients with treatment naïve CLL. ${ }^{24}$ Thalidomide (100 mg, $200 \mathrm{mg}$, and $300 \mathrm{mg}$ ) every day orally was given with fludarabine $\left(25 \mathrm{mg} / \mathrm{m}^{2}\right.$ intravenously for 5 days every 4 weeks) for 6 months. Overall the combination of fludarabine and thalidomide was well tolerated, fatigue (76.9\%), constipation $(61.5 \%)$, and peripheral sensory neuropathy $(61.5 \%)$ being the most frequently observed toxicities. Common hematological toxicities of this combination included thrombocytopenia (54\%), anemia (38\%), and neutropenia (31\%). Tumor flare reaction (TFR) was noted in $(46 \%)$ of the patients. However, all the patients who developed flare were able to complete scheduled treatment. Two patients developed pulmonary embolism. ${ }^{24}$ The overall response rate (ORR) of this combination was $100 \%$ with complete remission (CR) rate of $57 \%$. This observation was further confirmed in another study conducted among patients with high-risk CLL. ${ }^{25}$ In this clinical trial 20 patients with treatment-naïve (Arm A) and 20 patients with previously treated (Arm B) CLL were enrolled; 13 patients had a high-risk cytogenetic profile and 36 had mutated $\mathrm{IgV}_{\mathrm{H}}$. Thalidomide was administered at $100 \mathrm{mg} /$ day, with fludarabine given at $25 \mathrm{mg} / \mathrm{m}^{2}$ intravenously every day for 5 days on a 4 -week cycle for a maximum of six cycles. As anticipated, responses were higher in Arm A vs Arm B with an ORR and CR rate of $80 \%$ and $25 \%$ vs $25 \%$ and $0 \%$, respectively. Thalidomide and fludarabine combination was also noted to demonstrate efficacy in high-risk cytogenetic CLL patients with an ORR of 39\%. Common toxicities included constipation (95\%), fatigue (100\%), and infectious complications (45\%). TFR was recorded in a total of ten patients but all of these side effects were of moderate intensity. ${ }^{25}$ In another clinical trial conducted by Kay et al the clinical activity of thalidomide alone was evaluated in patients with relapsed or refractory CLL. ${ }^{26}$ In contrast to the other studies, TFR was the major toxicity reported in this study, warranting discontinuation of therapy in most patients and eventually early termination of the study due to lack of accrual. ORR and CR of thalidomide alone in this patient population were $11 \%$ and $4 \%$, respectively. Based on this study, the activity of single-agent thalidomide in patients with relapsed CLL is considered suboptimal due to low response rates, although $78 \%$ of patients demonstrated decrease in peripheral blood leukemic counts on treatment with thalidomide. ${ }^{26}$ These clinical trials set the stage for evaluation of the more potent thalidomide analog, lenalidomide.

Lenalidomide was first evaluated in relapsed or relapsed and refractory CLL patients through a phase II clinical trial. ${ }^{27}$ Important patient characteristics included median of three prior therapies (51\% fludarabine refractory), with advanced Rai stage disease in $64 \%$ of the patients. The starting dose in the initial cohort of patients $(n=29)$ was $25 \mathrm{mg} /$ day, but due to high incidence of hematological toxicities subsequent patients $(n=16)$ were started at a lower dose of lenalidomide $(10 \mathrm{mg} /$ day) with dose escalation of $5 \mathrm{mg} /$ day every 2 weeks as tolerated to a maximum of $25 \mathrm{mg} /$ day. The study schema allowed addition of rituximab $\left(375 \mathrm{mg} / \mathrm{m}^{2}\right)$ when patients progressed on lenalidomide alone. The ORR of single-agent lenalidomide in this patient population was $57 \%, 9 \%$ of patients achieving CR. Clinical responses were observed irrespective of high-risk (47\%) or bulky disease (40\%). ${ }^{28}$ Hematological toxicities reported include neutropenia in 76\% and thrombocytopenia in $51 \%$ of patients respectively. TFR is an important side effect of IMiDs therapy previously not known and seems to be predominantly noted in patients with lymphoproliferative disorder. The phenomenon is suggestive of host immune activation mimicking an inflammatory response. ${ }^{29}$ The overall incidence of TFR was $67 \%$, with grade 3 TFR noted among $10 \%$ of the patients. ${ }^{30}$ We also observed tumor lysis syndrome in $5 \%$ of patients. ${ }^{31}$

A subsequent phase II clinical trial, led by Ferrajoli and colleagues, validated the primary observation made with lenalidomide in CLL. ${ }^{32}$ This phase II trial also focused on patients with relapsed CLL with the starting dose of lenalidomide at $10 \mathrm{mg}$ given every day continuously. The dose of lenalidomide was escalated by $5 \mathrm{mg}$ every 28 days to a maximum of $25 \mathrm{mg} /$ day. The ORR reported in this clinical trial was $32 \%$, with CR rate of $7 \%$. Responses were observed in CLL patients with high-risk cytogenetics (ORR $31 \%$ ) or unmutated $\operatorname{IgV}_{\mathrm{H}}(24 \%)$ or those with fludarabinerefractory disease $(25 \%) \cdot{ }^{33}$ Recent clinical investigation is also focusing on the use of lenalidomide in previously untreated CLL patients either alone or in combination with other antiCLL therapeutics. ${ }^{34,35}$ Chen et al evaluated the efficacy of lenalidomide in treatment naïve patients with CLL. ${ }^{34}$ The study enrolled 25 patients with a median age of 60 years 
(range 33-78); 44\% of patients had Rai stage III/IV disease, $36 \%$ had bulky lymphadenopathy and adverse cytogenetics ( $17 \mathrm{p}$ or $11 q)$ were noted among $32 \%$ of patients. The study schema allowed for an initial starting dose of $10 \mathrm{mg}$ once daily with weekly escalation of $5 \mathrm{mg}$ to a maximum tolerated dose (MTD) of $25 \mathrm{mg} /$ day for 21 days of a 28-day cycle. Due to severe complications (tumor lysis in one patient requiring dialysis and death of another patient from neutropenic sepsis) the study was amended to an initial starting dose of $2.5 \mathrm{mg}$ and a slower escalation to a $10 \mathrm{mg}$ target dose. Important drug-related toxicities include grade $\geq 3$ neutropenia ( $43 \%$ of patients) and thrombocytopenia (13\% of patients). TFR was recorded in (80\%) of the patients (all reported as grade 1-2). ORR was $65 \%$, eleven patients achieving partial response (PR). ${ }^{36}$ Collectively these studies confirmed the clinical effectiveness of lenalidomide as a single agent in patients with CLL. Ongoing phase III studies are investigating the role of lenalidomide as monotherapy in previously untreated CLL.

Preclinical evaluations suggest that lenalidomide may be an important partner with immunotherapeutics. Ferrajoli et al reported the clinical efficacy of lenalidomide in combination with rituximab in relapsed CLL. Rituximab was administered $375 \mathrm{mg} / \mathrm{m}^{2}$ weekly (days $1,8,15,22$ ) and then once every month from cycle 3-12 on a 4-weekly schedule along with lenalidomide $10 \mathrm{mg}$ every day beginning day 9 of the first treatment cycle. The study enrolled 60 patients with a median age of 59 years (range 44-83) with median of 2 prior treatments range (1-9). Advance stage (Rai stage III/ IV) was noted in $41 \%$ of the patients, high-risk disease as defined by unmutated $\mathrm{IgV}_{\mathrm{H}}$ and $\operatorname{del}(17 \mathrm{p}$ ) was present in $70 \%$ and $24 \%$ of patients, respectively. ORR was $68 \%$ without any CR. ${ }^{35}$ Recently results of lenalidomide in combination with ofatumumab were also reported. The study evaluated the combination of immune therapies in relapsed CLL. Important characteristics include median age of 62 years (range 45-82), median of 2 (range 1-8) before treatment, $25 \%$ had fludarabine refractory, $31 \%$ had $\operatorname{del}(17 \mathrm{p})$ and $19 \%$ had del(11q). Ofatumumab was administered intravenously weekly for 4 consecutive weeks (300 mg week 1, $1000 \mathrm{mg}$ week 2 , and all subsequent doses, then monthly for months 2-6 and then once every 2 months for months 7-24). Lenalidomide was given orally at $10 \mathrm{mg}$ daily starting on day 9 and continued daily. Adverse side effects included grade $\geq 3$ anemia ( $13 \%$ of patients) and neutropenia ( $50 \%$ of patients). TFR grade 1-2 was noted among $13 \%$ of patients. ORR reported was $63 \%$, with $13 \% \mathrm{CR}$ and $50 \% \mathrm{PR}^{37}$

Tumor cell microenvironment remains an important therapeutic target, and manipulation of the microenvironment using the IMiDs has demonstrated impressive clinical activity. Furthermore, combination of these molecules with chemotherapeutics or immunotherapeutics has also significantly improved clinical responses even in patients with cytogenetic features of high-risk disease.

\section{Targeting the surface molecule Monoclonal antibodies}

The unique antigens present on the CLL cell surface have enabled development of additional therapeutic targets. The successful surface targets therapeutically exploited include the CD20 and CD52 antigens for which therapeutic monoclonal antibodies (rituximab and alemtuzumab respectively) have proven clinical efficacy, resulting in US Food and Drug Administration (FDA) approval. The success of the monoclonal antibodies ( $\mathrm{mAb}$ ) in CLL has resulted in exploitation of new targets on the CLL clone including CD19, CD25, CD40, CD37, and Apol/TRAIL as well as novel epitopes on the CD20 molecule.

\section{Mechanism of action}

The precise mechanism of action of $\mathrm{mAb}$ in killing cancer cells is variable and depends on the target antigen as well as the potential role of the $\mathrm{mAb}$ in response to the host immune system. Some of these mAbs execute direct tumor cell killing by activating effector mechanisms such as complement dependent cytotoxicity (CDC), antibody-dependent cellular cytotoxicity (ADCC), while others are tumoricidal as a result of directly providing apoptotic intracellular signals. ${ }^{38}$ The mAbs have also demonstrated ability to enhance the sensitivity of tumor cells in combination with traditional chemotherapies, resulting in significant improvement in clinical effects. Some of the clinically relevant $\mathrm{mAbs}$ are discussed here (Table 1).

\section{Targeting CD20}

CD20 is an important antigen expressed by B cell lymphoproliferative disorders including CLL. Rituximab is a chimeric anti-CD20 mAb, which has shown efficacy in patients with CLL. The activity of single-agent rituximab in CLL is modest at standard doses with ORR from $15 \%$ to $25 \% .{ }^{39}$ O'Brien et al reported a dose-response association with an ORR of $40 \% ; 22 \%$ in $500-825 \mathrm{mg} / \mathrm{m}^{2}, 43 \%$ in $1000-1500 \mathrm{mg} / \mathrm{m}^{2}$, and $75 \%$ in $2250 \mathrm{mg} / \mathrm{m}^{2}(P=0.007) .{ }^{40}$ The major impact of targeting the CD20 has been shown in combination with conventional chemotherapy. This has resulted in improved ORR, CR rate, and survival advantage. ${ }^{41}$ In this context the most effective combination strategy is the FCR regimen, as 
Table I Monoclonal antibodies in CLL

\begin{tabular}{|c|c|c|c|c|c|c|}
\hline \multirow[t]{2}{*}{ Study } & \multirow[t]{2}{*}{ Patient population } & \multirow[t]{2}{*}{ Treatment regimen } & \multicolumn{3}{|c|}{ Response (\%) } & \multirow{2}{*}{$\begin{array}{l}\text { Median DOR } \\
\text { (months) }\end{array}$} \\
\hline & & & OR & CR & PR & \\
\hline O'Brien et $\mathrm{a}^{40}$ & Relapsed CLL & Rituximab dose escalation & $36^{a}$ & 0 & 36 & 8 \\
\hline Tam et al ${ }^{43}$ & Untreated CLL & $\begin{array}{l}\text { Fludarabine, cyclophosphamide, } \\
\text { rituximab (FCR) }\end{array}$ & 95 & 72 & $10^{\mathrm{b}}$ & 80 \\
\hline \multirow[t]{2}{*}{ Wierda et $\mathrm{al}^{48}$} & Relapsed CLL & Ofatumumab single agent & $58^{c}$ & 0 & 58 & $5.7^{\mathrm{d}}$ and 5.9 \\
\hline & & & 47 & I & 47 & \\
\hline \multirow[t]{2}{*}{ Wierda et a $\mathrm{a}^{49}$} & Untreated CLL & Ofatumumab, fludarabine, & $77^{e}$ & $32^{f}$ & NR & Not reached \\
\hline & & cyclophosphamide (O-FC) & 73 & 50 & NR & \\
\hline Morschhauser et $\mathrm{al}^{51}$ & Relapsed CLL & Afutuzumab single agent & 62 & $I^{8}$ & $7^{\mathrm{h}}$ & Not reached \\
\hline Morschhauser et al ${ }^{53}$ & $\begin{array}{l}\text { Relapsed non-Hodgkin's } \\
\text { lymphoma }\end{array}$ & Veltuzumab single agent & 0 & 0 & 0 & Not reached \\
\hline Osterborg et a ${ }^{56}$ & Relapsed CLL & Alemtuzumab single agent & 42 & $4^{i}$ & 38 & 12 \\
\hline Nabhan et al ${ }^{57}$ & Relapsed CLL & $\begin{array}{l}\text { Alemtuzumab and rituximab } \\
\text { combination* }\end{array}$ & 52 & 8 & $40^{\mathrm{i}}$ & 6 \\
\hline Furman et $\mathrm{al}^{64}$ & Relapsed CLL & Dacetuzumab single agent & NR & 0 & $0^{k}$ & NR \\
\hline Woodworth et al ${ }^{66}$ & Relapsed CLL & Lumiliximab & NR & 0 & $0^{1}$ & NR \\
\hline Byrd et al ${ }^{67}$ & Relapsed CLL & $\begin{array}{l}\text { Lumiliximab in combination } \\
\text { with FCR }\end{array}$ & 71 & 48 & 10 & NR \\
\hline Frankel et $\mathrm{al}^{71}$ & Relapsed CLL & Ontak single agent & NR & 0 & $17^{\mathrm{m}}$ & NR \\
\hline
\end{tabular}

Notes: ${ }^{\mathrm{a}} \mathrm{OR}$ was $36 \%$ and ranged between $22 \%$ and $75 \%$; ${ }^{\mathrm{b} P R}$ nodular in $10 \%$, PR due to cytopenias in $7 \%$, and PR with residual disease in $6 \%$; ${ }^{\mathrm{c}, \mathrm{O}} \mathrm{OR}$ were $58 \%$ and $47 \%$ in the FA-ref and BF-ref groups, I CR in the BF-ref group otherwise all responses were PR, median duration of response was 5.7 months in the FA-ref group and 5.9 months in the BF-ref group; , efOR was $77 \%$ and CR was $32 \%$ for group A receiving ofatumumab at $500 \mathrm{mg}$ after initial dose of 300 mg in combination with fludarabine and cyclophosphamide, OR was $73 \%$ and CR was $50 \%$ for group B receiving ofatumumab at $1000 \mathrm{mg}$ after initial dose of $300 \mathrm{mg}$ in combination with fludarabine and cyclophosphamide; both groups received total of 6 cycles; g.h CRi I and 7 PR was reported; 'CR attained in bone marrow in $36 \%$ of patients; 'alemtuzumab was given at escalating dose to a maximum of 30 $\mathrm{mg}$ in combination with rituximab, PR $40 \%$ and partial remission nodular (PRn) was 4\%; ${ }^{k}$ No patients achieved objective response, 5 patients demonstrated stable disease; 'reductions in lymphocyte counts were noted in $91 \%$ and reduction in size of lymph nodes was noted in $59 \%$ of patients; ${ }^{\mathrm{mPR}}$ was reported as $17 \%$ and $58 \%$ minimal responses, progression free interval in responders ranged between I and 19+ months.

Abbreviations: CR, complete response; CCL, chronic lymphocytic leukemia; DOR, duration of response; NR, not reported; OR, overall response; PR, partial response.

reported by Keating et al, Wierda et al, and Tam et al.,52,43 This combination resulted in ORR and CR rates of $95 \%$ and $72 \%$, respectively. Hallek et al recently reported a follow-up study comparing this chemoimmunotherapy regimen with chemotherapy-only combination (FC). ${ }^{44}$ This phase III clinical study confirmed the benefit of adding anti-CD20 mAb and thus the importance of target-specific therapy in patients with CLL. The impressive results of incorporating target directed anti-CD20 mAb into anti-CLL treatment regimens has fueled the development of several new mAbs including new antiCD20 molecules (ofatumumab, afutuzumab, veltuzumab) with improved target binding (Table 1)..$^{45}$

Ofatumumab (HuMax-CD20) is a fully humanized mAb, also designed to target the CD20 molecule on CLL cells. In comparison with rituximab, ofatumumab recognizes a novel epitope on the CD20 molecule that is localized in the second extracellular loop, distinct from the site recognized by rituximab. Ofatumumab has demonstrated superior antitumor effects in vitro with the ability to induce CDC in rituximab resistant cells. ${ }^{45,46}$ Fludarabine refractory disease remains a challenging group among CLL patients with limited treatment options. In an international multicenter study $(\mathrm{n}=138)$ clinical activity of ofatumumab was evaluated in patients with fludarabine and alemtuzumab refractory disease. ${ }^{47}$ The patient population evaluated in this trial included a group with refractory disease to both fludarabine and alemtuzumab therapy (FA-ref) $(n=59)$ and another group with bulky disease refractory to fludarabine therapy (BF-ref) $(n=79)$. Other important clinical characteristics include median of five and four prior therapies, advanced Rai stage III and IV among $54 \%$ and $69 \%$ of patients, high-risk cytogenetics $\operatorname{del}(17 \mathrm{p})$ and $\operatorname{del}(11 \mathrm{q})$ were noted among $28 \%$ and $17 \%$, and $40 \%$ and $27 \%$, in the FA-ref and BF-ref groups, respectively. Ofatumumab was administered intravenously weekly for 8 weeks followed by monthly infusions for 4 months for a total of 24 weeks (dose $1=300 \mathrm{mg}$, doses $2-12=2000 \mathrm{mg}$ ). The study demonstrated activity of ofatumumab in FA-ref as well as BF-ref patients with ORRs of $58 \%$ and $47 \%$, respectively. CR was also reported in one patient. Patients with del(17p) were noted to have lower responses. The median progressionfree survival and overall survival were 5.7 and 5.9 months, and 13.7 and 15.4 months, in the FA-ref and BF-ref groups, respectively. The most common toxicities during treatment were infusion-related reactions ( $\sim 60 \%)$ and infections (74\%). Updated results showed ORR of $51 \%$ for the FA-ref group and $44 \%$ for the BF-ref group. ${ }^{48}$ These results formed the basis for 
approval of ofatumumab for CLL patients with fludarabine/ alemtuzumab-resistant disease. Ofatumumab has also been evaluated in combination with FC as front-line treatment. ${ }^{49}$ Wierda et al reported the efficacy of two doses of ofatumumab (500 mg; group A or 1000 mg; group B) in combination with FC regimen. ORR and CR rates were $77 \%$ and $73 \%$ in group A and $32 \%$ and $50 \%$, respectively. ${ }^{49}$ (Table 1 ).

Afutuzumab (GA-101) is a third-generation humanized $\mathrm{mAb}$ developed for the treatment of B cell malignancies. Afutuzumab is the first glycol engineered, type II anti-CD20 mAb to enter into phase I/II clinical trials. Afutuzumab works by binding to the type II epitope localized in the CD20 extracellular loop, causing enhanced direct cell apoptosis and ADCC. ${ }^{50}$ The clinical activity of afutuzumab has been demonstrated in relapsed CLL. The important patient characteristics included a median of three prior treatments, high-risk cytogenetic del(17p) or del(11q) in $33 \%$ of patients, and $70 \%$ of patients had unmutated $\operatorname{IgV}_{\mathrm{H}}$. Afututzumab was administered at 400-2000 mg intravenously in a safety driven dose-escalating design on days 1, 8, and 22 repeated every 3 weeks for a total of nine infusions. The drug demonstrated antileukemic activity as manifested by depletion of B cells following the first infusion. The ORR was $62 \%$ with $1 \mathrm{CR}$ and $7 \mathrm{PR} .{ }^{51}$ Grade 1-2 toxicities were infusion-related reactions including fever, chills, hypotension, and nausea, which were manageable with steroids. Grade 3-4 hematological events included transient neutropenia in nine patients, febrile neutropenia in one, and one patient was reported to develop transient thrombocytopenia. ${ }^{51}$ Veltuzumab is a humanized second-generation anti-CD20 mAb with structural similarities to rituximab, except for a single amino acid difference in the CDR3-VH region. Veltuzumab is currently under development for the treatment of B cell lymphoproliferative disorders. ${ }^{52}$ Veltuzumab has shown modest activity in a small cohort of CLL patients. However, in preclinical studies this agent showed favorable data and efficacy in lymphoproliferative disorders. ${ }^{52-54}$

\section{Targeting CD52}

Alemtuzumab is a humanized mAb that targets CD52 antigen. The antiproliferative effects of alemtuzumab are postulated to act mainly via CDC and ADCC, although the exact mechanism remains to be defined. Alemtuzumab was approved by the FDA based on a pivotal trial, which demonstrated its efficacy in patients with fludarabine-refractory CLL. ${ }^{55}$ In a pivotal trial of relapsed CLL alemtuzumab was administered at $3 \mathrm{mg}$ in dose escalation to $30 \mathrm{mg}$ intravenously three times weekly for a maximum of 12 weeks $(n=93)$. Prophylaxis with co-trimaxazole and acyclovir was mandatory. The study demonstrated efficacy, with an ORR of 33\% (CR $2 \%$; PR 31\%) with overall median survival of 16 months and median survival for responders reported as 32 months. Most commonly encountered adverse events were infusionrelated and included grade $<2$ rigors and fevers. Infectious complications reported were grade 3-4 infections in $26.9 \%$, cytomegalovirus reactivation in seven, grade 2 infection in three, and grade 3 infections in four patients. ${ }^{55}$ Similarly activity of alemtuzumab in relapsed CLL was demonstrated by Osterborg et al, with an ORR of $42 \%, 4 \%$ of patients achieving $\mathrm{CR}$ and $38 \%$ PR. Important hematological toxicities included grade 4 neutropenia in 10\% and thrombocytopenia in $7 \%$ of patients. Infectious complications included two opportunistic infections and four bacterial septicemias. Infusion-related toxicities such as fever and rigors were also reported in the first week of administration and were easily managed with anti-inflammatory medications. ${ }^{56}$ Combination of alemtuzumab with other mAbs and cytotoxic agents has also been reported but efficacy was variable. ${ }^{57}$ An important limitation of alemtuzumab seems to be limited efficacy in patients with bulky disease, the underlying mechanism of which remains unknown. Hillmen et al reported the clinical efficacy of alemtuzumab in previously untreated CLL patients in a randomized phase III trial (CAM 307). ${ }^{58}$ Patients were randomized to receive either alemtuzumab $(30 \mathrm{mg}$ three times weekly for 12 weeks) or oral chlorambucil ( $40 \mathrm{mg} / \mathrm{m}^{2}$ every 28 days for a maximum of 12 months). The ORR reported with alemtuzumab was $83 \%$ with $24 \% \mathrm{CR}$, whereas the ORR in the chlorambucil group was $55 \%$ with $2 \%$ of patients attaining CR. The incidence of adverse events was comparable between both the groups, with infusion-related toxicity and cytomegalovirus infection being higher for the patients taking alemtuzumab. ${ }^{58}$ Alemtuzumab has demonstrated significant activity in patients with the $\operatorname{del}(17 \mathrm{p})$. This effect is not as readily observed with other monoclonal antibodies or nucleoside analogs. Currently, alemtuzumab remains the only FDA-approved agent available with activity in patients with $\operatorname{del}(17 \mathrm{p})$ who lack function of the p53 gene (Table 1). ${ }^{59}$

\section{Targeting CDI 9}

$\mathrm{XmAb5574}$ is a novel engineered anti-CD19 mAb with a modified constant fragment ( $\mathrm{Fc}$ )-domain designed to enhance binding of FcyRIIIa. The mechanism of action includes potent ADCC. The ADCC is mediated by NK cells through a granzyme B-dependent mechanism. Preclinical data appear promising and are associated with significant activity in CLL. It is currently being evaluated in a phase I clinical trial (Table 2). ${ }^{60}$ 


\section{Targeting CD37}

CD37 is a member of the tetraspanain family involved in regulation of key cellular functions such as activation, proliferation, and cell-cell adhesions. TRU-016 is a novel small compound that targets CD37 and induces cell killing by augmenting the functions of NK cells and inducing Fc-mediated cellular cytotoxicity. TRU-016 has been investigated in patients with relapsed CLL. ${ }^{61,62}$ This phase I study included 57 patients of median age of 66 years, Rai stage III-IV disease was present in $68.5 \%$, and high-risk cytogenetics del(17p) or del(11q) were present in $38 \%$ and $21 \%$ of the patients, respectively. ${ }^{61}$ TRU-016 was administered in nine doses, which ranged from 0.03 to $20 \mathrm{mg} /$ $\mathrm{kg}$ intravenously once a week for 4-12 doses followed by second schedule doses of 3,6 , or $10 \mathrm{mg} / \mathrm{kg}$ on days 1,3 , and 5 on the first week followed by 3-11 weekly doses. MTD was not reached. Important toxicities included febrile neutropenia (3), pneumonia (3), infusion reactions (2), pyrexia (2), and (2) dyspnea. Neutropenia was reported as the dose limiting toxicity. Updated results demonstrated that patients with one or two prior therapies demonstrated a superior ORR of $44 \% .{ }^{61}$ Patients with $>3$ prior treatments failed to demonstrate any objective responses except for reduction in lymphocyte count of $67 \%$ (Table 2 ) ${ }^{61}$

\section{Targeting CD40}

CD40 is a member of the TNF family expressed on normal and malignant B cells. Dacetuzumab (SGN-40) is a humanized $\mathrm{mAb}$ against $\mathrm{CD} 40$. Dacetuzumab has shown activity in relapsed non-Hodgkin's lymphoma (NHL) ${ }^{63}$ A preliminary phase I study demonstrated clinical activity in patients with lymphoproliferative disorder. The study schema included 50 patients with relapsed B-cell NHL (diffuse large B cell $42 \%$, follicular $24 \%$, mantle cell $20 \%$, small lymphocytic lymphoma $2 \%$, other $6 \%$ ) with a median of three prior treatments (range 1-8). Dacetuzumab was administered intravenously from $2 \mathrm{mg} / \mathrm{kg}$ weekly for 4 weeks to dose escalation of $8 \mathrm{mg} / \mathrm{kg}$ to different patient cohorts. MTD was not established at the dose levels tested. Reported side effects in $>20 \%$ of patients were fatigue, pyrexia, and headache, and noninfectious inflammatory eye disorder occurred in $12 \%$ of patients. The ORR observed in these patients was $12 \%$ with $1 \mathrm{CR}$ and 5 PR. ${ }^{63}$ Additionally, there was no dose-response relationship. Furman et al reported a phase I study of dacetuzumab in relapsed CLL. ${ }^{64}$ This study included twelve patients with relapsed CLL who had received a median of four prior treatments (range 2-11). The patients were administered dacetuzumab starting at $3-8 \mathrm{mg} / \mathrm{kg}$ in a dose escalation manner. The most common adverse effects were fatigue, headache, anorexia, conjunctivitis, hyperhidrosis, and night sweat. Although no objective response was identified, $41 \%$ of patients showed stable disease (Table 1) ${ }^{64}$

\section{Targeting CD23}

Lumiliximab is a primatized monoclonal antibody that targets the CD23 antigen and mediates a ADCC and CDC. ${ }^{65}$ Lumiliximab has demonstrated antileukemic activity in CLL. In a phase I trial for patients with relapsed CLL, lumiliximab demonstrated decrease in lymphocyte counts in $91 \%$ of patients and reduction in lymphadenopathy in $59 \%$ of patients. ${ }^{66}$ This was followed by a phase I/II trial in which lumiliximab was given in combination with the FCR regimen to patients with relapsed CLL. ${ }^{67}$ This study enrolled 31 patients and lumiliximab was administered at $375 \mathrm{mg} / \mathrm{m}^{2}$ $(\mathrm{n}=3)$ or $500 \mathrm{mg} / \mathrm{m}^{2}(\mathrm{n}=28)$ in combination with FCR for six cycles. ORR was $71 \%, 48 \%$ of patients showing CR and $10 \%$ achieving PR (Table 1) ${ }^{67-69}$ The most common side effects were nausea and pyrexia. Although the initial results were promising, subsequent studies did not validate the findings and an ongoing international multicenter phase III trial (LUCID) was halted due to the lack of efficacy of lumiliximab.

\section{Targeting CD25 (IL-2R)}

The immunotoxin denileukin diftitox (Ontak; Eisai Inc.) is a recombinant protein attached to the diphtheria toxin

Table 2 Preclinical agents in CLL

\begin{tabular}{lllll}
\hline Drug & Oncogene or antigen & Mechanism of action & Developmental phase & Study \\
\hline ABT-737 & Bak/Bax & Restores apoptosis & Phase I/II & van Delft et al $^{16}$ \\
A-443654 & Akt & Restores apoptosis & Phase I & de Frias et al ${ }^{100}$ \\
Geldanamycin & Hsp 90 & Restores apoptosis & Phase I & Lin et al $^{107}$ \\
Mapatumumab & TRAIL & Restores apoptosis & Phase I & Natoni et al $^{80}$ \\
TRU-016 & CD37 & ADCC & Phase I & Furman et al $^{61}$ \\
XmAb5574 & CDI9 & ADCC & Phase I & Awan et al $^{60}$ \\
\hline
\end{tabular}

Abbreviations: ABT-737, isomer of gossypol; Akt, protein kinase; Hsp 90, heat shock protein; TRAIL, tumor necrosis factor related ligand; XmAb5574, anti-CDI9 monoclonal antibody; ADCC, antibody-dependent cellular cytotoxicity; CLL, chronic lymphocytic leukemia. 
along with IL-2 targeting mAb. The antitumor activity is mainly mediated by binding to IL-2 receptors and releasing the diphtheria toxin. Denileukin diftitox has shown clinical efficacy in hematological malignancies and has been approved for the treatment of T-cell lymphomas. ${ }^{70}$ Frankel et al reported the activity of denileukin diftitox in relapsed CLL patients with CD25 expression of $>20 \%{ }^{71}$ Patients were treated with daily infusion of denileukin diftitox at $18 \mu \mathrm{g} / \mathrm{kg} /$ day for 5 days every 21 days for eight cycles. Of a total of 30 treated patients, 22 exhibited 73\% CD25 expression on at least $20 \%$ of circulating cells. Patients had received a median of four prior treatments (range 1-11). The treatment was well tolerated with important toxicities reported as asymptomatic elevation of transaminases (17), fever (11), fatigue (11), hypoalbuminemia (10), nausea and vomiting (7), myalgias (4), rash (4), anorexia (2), vascular leak syndrome (2), elevated creatinine (1), and anaphylactic reaction (1). Patients on denileukin diftitox demonstrated PR of $8 \%, 50 \%$ showing minimal response. ${ }^{71}$ Morgan et al reported activity of denileukin diftitox in relapsed CLL patients irrespective of CD25 status. Seven patients with refractory CLL and CD25 negative status were treated with Ontak on the standard regimen of $18 \mu \mathrm{g} / \mathrm{kg}$ intravenously for 5 days repeated every 3 weeks or every 21 days. All patients experienced some toxicities such as serositis, hypoalbuminemia and asthenia. This study showed activity in heavily pretreated CLL patients with two objective PR and two minimal responses (Table 1). ${ }^{72}$

\section{Targeting the death receptor TRAIL}

Death receptors have also been targeted to induce apoptosis in hematological malignancies. Apoptosis 2 TNF-related apoptosis-inducing ligand (Apo2/TRAIL) is a protein ligand in the TNF family which binds to the death receptors TRAIL-R1 and TRAIL-R2. Along with Fas, TNF- $\alpha$ is the key component of extrinsic apoptotic cell death pathways. The extrinsic pathway is activated once the ligands bind to the death receptors and assemble the death-inducing signaling complex on the cell surface, which transmits the signals necessary to initiate apoptosis. ${ }^{73} \mathrm{CLL}$ and other B cell malignancies are noted to demonstrate resistance to TRAIL due to possible lack of functional receptor or overexpression of inhibitory molecules. ${ }^{74-76}$ Apo2/TRAIL is a homodimeric protein ligand of the tumor necrosis factor (TNF) family that binds to the death receptors TRAIL-R1 and TRAIL-R2 to activate extrinsic apoptotic death pathways. Mapatumumab has shown in vitro efficacy in different hematological malignancies. ${ }^{77,78}$ Mapatumumab has also shown efficacy in patients with NHL. ${ }^{79}$ In a phase II study of pretreated NHL patients $(\mathrm{n}=40)$, mapatumumab was administered at $3 \mathrm{mg} /$ $\mathrm{kg}$ or $10 \mathrm{mg} / \mathrm{kg}$ intravenously every 21 days for a total of six cycles. Mapatumumab treatment resulted in $8 \%$ ORR (1 CR, 2 PR) in the follicular lymphoma subgroup, with only stabilization of disease in other subgroups. Overall, mapatumumab was reported to be well tolerated. Additionally, anti-TRAIL antibodies are also showing synergistic effects with other agents such as histone deacetylase inhibitors, which in turn have been shown to enhance sensitivity of CLL cells against TRAIL receptors. ${ }^{74,80}$ Preclinical studies with histone deacetylase inhibitors such as depsipeptide and trichostatin A are noted to induce apoptosis by increasing sensitivity of malignant cells to TRAIL by causing increased expression of death receptors and a decrease in expression of inhibitory proteins such as c-FLIP, c-IAP2, and XIAP ${ }^{81-83}$ The utility of compounds working on the death ligand in cancer therapy may become another potential option to overcome antiapoptotic effects, which are noted to cause resistance to the current treatment (Table 2).

\section{Targeting BCR-mediated signaling}

BCR is crucial in CLL biology due to association with downstream signaling pathways such as PI3K, Akt, and proteins like RAS and MAP kinases. It has been demonstrated that interaction between CLL cells and lymph node microenvironment regulates proliferation of CLL cells through chemokine-induced BCR signaling and $\mathrm{NF} \kappa \mathrm{B}$ activation through canonical pathways resulting in c-myc activation. ${ }^{84}$ BCR signaling is mediated through phosphorylation of spleen tyrosine kinase in normal and malignant B cells. The spleen tyrosine kinase inhibitor fostamatinib has been evaluated in patients with recurrent NHL including CLL. ${ }^{85}$ Fostamatinib was administered orally at $200 \mathrm{mg}$ or $250 \mathrm{mg}$ twice daily dosing schedule in the phase I and at $200 \mathrm{mg}$ twice daily schedule in the phase II portion of the study. Therapy was continued for 4 weeks and the dose limiting toxicities reported were diarrhea, neutropenia, and thrombocytopenia. In the phase II cohort ORR was 55\% and 6/11 patients with CLL demonstrated a PR. Median duration of response was 6.5 months. Important toxicities reported include grade 3 and 4 anemia (7\%), neutropenia (18\%), and thrombocytopenia (3\%). ${ }^{85}$ Tyrosine kinase inhibitors such as dasatinib and imatinib have changed the paradigm of treatment for chronic myeloid leukemia. Preclinical work with dasatinib in CLL appears promising and showed induction of apoptosis by inhibiting Akt and MAP kinase pathways. However this has not been translated into clinical care of patients to date. ${ }^{86,87}$ 
Ongoing research promises to further explore the role of tyrosine kinase inhibitors in CLL.

\section{Targeting intracellular proteins $\mathrm{Bcl}-2$ inhibitors}

The Bcl-2 family comprises a group of proteins involved in the regulation of programmed cell death by modulating the mitochondrial membrane permeability in apoptosis. The Bcl-2 family is comprised of anti- and propapoptotic proteins functioning to preserve the mitochondrial integrity or promoting the release of cytochrome $\mathrm{C}$ from the mitochondrial membrane. The members of this family mirror each other in the homology domains (BH 1-4) and proteins are subdivided into three major classes. Functionally, members of the Bcl-2 family can be divided into the antiapoptotic (Bcl-2, Bcl-xl) and proapoptotic proteins (Bax, $\mathrm{Bak}$, and the $\mathrm{BH} 3)$. Increased $\mathrm{Bcl}-2$ expression is observed in B cell malignancies including CLL and is associated with resistance to apoptosis. ${ }^{12,88}$ Clinically, this translates into aggressive disease and chemotherapy resistance. Elimination of Bcl-2 has the potential to facilitate cancer cell destruction and offers a viable therapeutic strategy. ${ }^{89}$ Several compounds are being investigated in clinical trials with the intent of inducing apoptosis by either activating the proapoptotic proteins or negating the antiapoptotic proteins. Some of these compounds include oblimersen sodium, HA14-1, obatoclax mesylate, AT-101, and ABT-737..$^{90}$

Oblimersen sodium is an antisense oligonucleotide that is comprised of a short sequence of single stranded deoxyribonucleic acids complementary to the Bcl-2 mRNA. Oblimersen has shown efficacy in CLL as well as other malignancies. ${ }^{14,91}$ In a phase I/II study, relapsed patients with CLL were given continuous infusion of oblimersen 3-7 mg/kg/day for a total of 5 days for the first cycle and 7 days for subsequent cycles. The dose limiting toxicity was cytokine release syndrome manifested by fever, rigors, and low blood pressure. The ORR was $8 \%$ but $>50 \%$ of patients demonstrated a notable decrease in spleen size, lymph nodes, and liver and/or lymphocyte counts. Subsequently in a randomized phase III study oblimersen plus FC chemotherapy was compared with FC chemotherapy alone in relapsed CLL patients. A total of 241 patients were randomly assigned to oblimersen plus FC chemotherapy group $(n=120)$ or chemotherapy-only group $(\mathrm{n}=121)$. Both groups were balanced for clinical characteristics. The chemotherapy-only group received fludarabine $25 \mathrm{mg} / \mathrm{m}^{2} /$ day intravenously followed by cyclophosphamide $250 \mathrm{mg} / \mathrm{m}^{2} /$ day intravenously on days $1-3$ of the treatment cycle. In the oblimersen group, oblimersen $3 \mathrm{mg} / \mathrm{kg} /$ day was administered on days 1 through 7 by continuous infusion and FC was administered at the doses described above on days 5, 6, and 7 every 28 days for up to 6 cycles. Important reported toxicities include grade 4 neutropenia (7\%) and (11\%) in the oblimersen and chemotherapy group versus chemotherapy-only group, respectively. Other toxicities included febrile neutropenia, hypotension, and thrombocytopenia seen among $2 \%$ of patients in both groups, although they were more common in the oblimersen plus chemotherapy group. The study reported a $17 \% \mathrm{CR} /$ nodular PR rate in the oblimersen group whereas this rate was only $7 \%$ in the chemotherapy-only group $(P=0.025)$. Thus oblimersen appears to enhance efficacy of the chemotherapeutics fludarabine and cyclophosphamide. The important factor in determining response was sensitivity to fludarabine treatment, which appears to enhance the efficacy by fourfold..$^{91}$ Most importantly, long-term follow-up demonstrated survival advantage in favor of patients receiving the Bcl-2 targeted therapy in combination with chemotherapy vs chemotherapy alone.

Obatoclax mesylate (GX15-070) is a synthetic pan Bcl-2 inhibitor shown to facilitate apoptosis by activation of Bax and Bak protein in patients with CLL. ${ }^{15,92,93}$ In a phase I study of relapsed CLL, patients $(n=26)$ with a median of four treatments were enrolled for treatment with obatoclax mesylate. Obatoclax mesylate was administered at doses ranging from 3.5 to $14 \mathrm{mg} / \mathrm{m}^{2}$ as 1 -hour infusion and from $20-40 \mathrm{mg} / \mathrm{m}^{2}$ as 3-hour infusion every 3 weeks for a total of 74 cycles. MTD was $28 \mathrm{mg} / \mathrm{m}^{2}$ over 3 hours every 3 weeks. Dose limiting toxicities were neurological and included euphoria, somnolence, and ataxia. PR was $4 \%$ and several patients demonstrated hematological improvements (3/11 with anemia and 4/14 with thrombocytopenia), and lymphocyte reduction was observed in $18 / 26$ patients. ${ }^{15}$ This compound holds promise and is continually being investigated in patients with CLL.

AT-101 is an orally available BH3 mimetic that has been demonstrated to induce apoptosis in CLL cell in vitro. ${ }^{94}$ AT-101 has demonstrated clinical efficacy and favorable toxicity as a single agent in treatment-naïve high-risk patients with CLL. James et al evaluated efficacy of AT-101 in a phase I clinical trial with treatment-naïve high-risk CLL, in which a total of seven patients were treated with AT-101 at doses ranging from 20 to $40 \mathrm{mg}$ daily. ${ }^{95}$ Important patient characteristics included: median age 55 years, elevated ZAP-70 (57\%), elevated CD38 (71\%), unmutated $\operatorname{IgV}_{\mathrm{H}}$ (57\%), trisomy $12(43 \%)$, and $\operatorname{del}(17 \mathrm{p})$ (43\%). AT-101 demonstrated antileukemic activity as evidenced by $5 / 6$ 
patients showing decrease in lymphocyte count, 6/6 having reduced lymphadenopathy, and 5/5 having palpable spleens with a reduction in spleen size. The most common adverse event reported was incidence of grade 3 elevation of transaminases among six patients. It was concluded that AT-101 was safe, with antileukemic activity among high-risk patients with CLL. ${ }^{95}$ AT-101 in combination with rituximab has been reported to exhibit enhanced cytotoxicity in CLL cells. ${ }^{94,96}$ In relapsed refractory CLL, AT-101 has yielded an ORR of $38 \% .{ }^{96}$ The treatment was well tolerated except for toxicities as manifested by paralytic ileus, fatigue, and neutropenia.

ABT-737 is an isomer of gossypol with the ability to target the Bcl-2 and induce apoptosis in preclinical models of B cell cancers (Table 2). The analog of ABT-737, ABT263 , is currently being investigated in the clinic and has also demonstrated activity against CLL cells in vitro. ${ }^{16,97}$ The earlier Bcl-2 inhibitors have demonstrated modest efficacy in cancer therapy, but the potential for newer pan Bcl-2 inhibitors appears promising due to improved target binding, bioavailability, and route of administration. ABT263 is currently evaluated in clinical trials for patients with lymphoid malignancies including CLL. In a phase I/II clinical study with relapsed CLL, two dosing schedules were evaluated of ABT-263 (intermittent dosing on days 1-14 of a 21-day schedule vs continuous dosing 21 days of a 21-day cycle). Responses among the 27 CLL patients included PR in $11 \%$ of patients, whereas $22 \%$ exhibited $>50 \%$ decrease in lymphocyte counts for $>2$ months and $40 \%$ of patients demonstrated stable disease. The important reported toxicities include dose-dependent thrombocytopenia due to target inhibition of Bcl-xl. ${ }^{98}$

\section{Akt inhibitors}

Protein, serine, and threonine kinases comprise several families of transmembrane and cytoplasmic receptors (receptor protein tyrosine kinases). The PI3 K pathway is an important cell survival route, which is aberrantly expressed in CLL. The PI3 K pathway activates the Akt/protein kinase B by phosphorylation. Akt, once activated, inhibits apoptosis by phosphorylating proteins such as Bad and procaspase 9 ,

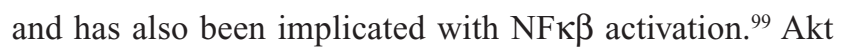
inhibitor constitutes an important therapeutic option in the arsenal of targeted drug therapy. Preclinical data have shown that Akt inhibitors can induce apoptosis in CLL cells. The Akt inhibitor A-443654 has been shown to cause an increase in levels of the BH3-only proteins NOXA and PUMA and a decrease in Mcl-1 levels, independent of p53 function.
The preclinical activity of these compounds is intriguing, with the possibility that the Akt inhibitors can add to the class of drugs inducing apoptosis and may complement the effects of other molecular targets to provide improve efficacy along with adding an option in high-risk patients identified by their defective p53 status (Table 2). ${ }^{100} \mathrm{CAL}-101$ is a PI3 K inhibitor currently being evaluated in preclinical studies and has been shown to promote apoptosis by abrogation of signals transmitted through CD40 L, BAFF, TNF $\alpha$, and fibronectin. ${ }^{101}$ The results of a phase I study were recently reported. CAL-101 was administered orally once or twice daily continuously for 28 days for a total of 12 months. The important clinical characteristics of patients included median age of 65 years (range 37-82), median of five prior therapies, 29 patients with bulky disease, and 22 patients with adverse cytogenetics del(17p) or del(11q). The study reported substantial decreases in the size of the lymph nodes, with $91 \%$ of patients showing a $>50 \%$ decrease in lymph-node size. PR was reported in $33 \%$ of patients. Median duration of response has not been reached. Adverse events reported include grade 3 pneumonias (24\%), neutropenia (24\%), thrombocytopenia (11\%), and anemia (8\%). ${ }^{102}$ Enzastaurin HCL is an oral kinase inhibitor which inhibits signaling associated with the PI3 K pathway; a phase I study in CLL is currently ongoing and results are awaited. ${ }^{103}$

\section{Heat shock protein inhibitors}

Heat shock proteins (HSP) are a group of cytoplasmic proteins essential in maintaining cellular homeostasis by virtue of their role in transcriptional regulation, chromatin remodeling, and regulation of key signaling pathways such as Akt, Raf-1, and ERB-2. ${ }^{104}$ HSP also assist with the folding of mitochondrial proteins and regulate proteolytic degradation of misfolded protein in an ATP-dependent manner. ${ }^{105}$ HSP and the helper protein known as the co-chaperon form a network which acts as a guardian for several oncoproteins facilitating tumor growth by regulating survival signal and inducing resistance to chemotherapy. Mammalian HSP are classified and named according to their molecular sizes into six families. ${ }^{105}$

Drugs targeting HSP are being evaluated in different malignancies. The ansamycin antibiotics geldanamycin and herbimycin A have demonstrated antileukemic activity. ${ }^{106}$ The exact mechanism of action of HSP is currently being explored in CLL but it has been suggested that this group exerts its effects possibly through depletion of Akt causing loss of survival signals, changes in p53 and p21, or depletion of ZAP-70 causing inhibition of prosurvival signals. ${ }^{107}$ 
In preclinical studies, the HSP inhibitor geldanamycin has shown induction of cell apoptosis irrespective of p53/ATM mutation status, suggesting a role in high-risk patients. The validation of preclinical activity of these compounds awaits results from clinical trials (Table 2).

\section{Cyclin-dependent kinase inhibitors}

Cyclin-dependent kinases (CDK) are important regulators of the cell cycle that controls transcription in different hematological malignancies. CDK inhibitors including alvocidib and SNS-032 have shown activity in CLL. Alvocidib (NSC649890) is derived from a plant and has shown substantial cytotoxicity on CLL cells in vitro. ${ }^{108}$ Alvocidib inhibits the antiapoptotic proteins including the Mcl-1, X-linked inhibitor of apoptosis, additionally inhibits the transcription by abrogating the functions of CDK9 and CDK7. In a phase I study alvocidib was administered as a 30-minute loading dose followed by 4-hour infusion administered weekly for 4 of 6 weeks in patients with refractory CLL. ${ }^{109}$ The study included 42 patients with refractory CLL in three cohorts. Alvocidib was administered as a $30 \mathrm{mg} / \mathrm{m}^{2}$ loading dose followed by $30 \mathrm{mg} / \mathrm{m}^{2}$ 4-hour infusion in cohort 1 ; cohort 2 , alvocidib $40 \mathrm{mg} / \mathrm{m}^{2}$ followed by $40 \mathrm{mg} / \mathrm{m}^{2}$ 4-hour infusion; cohort 3, alvocidib $30 \mathrm{mg} / \mathrm{m}^{2}$ loading dose followed by $30 \mathrm{mg} / \mathrm{m}^{2}$ 4-hour infusion for treatments $1-4$ then a $30 \mathrm{mg} / \mathrm{m}^{2}$ loading dose followed by $50 \mathrm{mg} / \mathrm{m}^{2}$ infusion. The dose limiting toxicity was hyperacute tumor lysis syndrome. In order to prevent tumor lysis aggressive prophylaxis and selection of patients with leukocyte count of $<200 \times 10^{9} / \mathrm{L}$ were taken which permitted dosing on cohort 3 . Out of the 42 treated patients PR was achieved in $45 \%$, and median duration of response exceeded 12 months. Responses were also observed in the high-risk group; $42 \%$ of the $\operatorname{del}(17 p)$ and $72 \%$ of $\operatorname{del}(11 q)$ patients demonstrated response. ${ }^{109}$ These results were validated in a multicenter international trial. This study included patients with fludarabine-refractory CLL or prolymphocytic leukemia. The important characteristics included median age of 61 years, $81 \%$ of patients with Rai stage III/IV, and $65 \%$ of patients with bulky lymphadenopathy, and adverse cytogenetics del(17p) or del(11q) were noted among $31 \%$ and $36 \%$ of patients, respectively. Alvocidib was given intravenously with an initial bolus of $30 \mathrm{mg} / \mathrm{m}^{2}$ followed by continuous infusion of $30 \mathrm{mg} / \mathrm{m}^{2}$ over 4 hours; in the absence of tumor lysis $50 \mathrm{mg} / \mathrm{m}^{2}$ over 4 hours continuous infusion was administered once weekly for 4 weeks followed by a 2 -week break for a total of six cycles. Adverse events included grade 3 febrile neutropenia (15\%), infections (32\%), diarrhea (17\%), and tumor lysis syndrome (19\%). Eight patients required hemodialysis for renal failure secondary to tumor lysis syndrome. The study reported responses, mainly PR, among 21 patients (31\%) using NCI-96 criteria and 17 patients $(25 \%)$ using the hybrid criteria. Median duration of response was 12.2 months for the responders. Responses among the high-risk group identified with del(17p13.1) were $25 \%$ and $19 \%$, with del(11q22.3) responses were $30 \%$ and $20 \%$, and with bulky lymphadenopathy responses $39 \%$ and $32 \%$ using the NCI-96 and hybrid criteria, respectively. ${ }^{110}$

SNS-032 is a selective inhibitor of CDKs 2, 7, and 9. In a phase I dose escalation study in relapsed CLL, SNS-032 was given at $22-100 \mathrm{mg} / \mathrm{m}^{2}$. Tumor lysis syndrome was observed in four patients treated at $75 \mathrm{mg} / \mathrm{m}^{2}$ and one patient treated with $100 \mathrm{mg} / \mathrm{m}^{2}$; however none of the patients required dialysis and there were no deaths from the treatment. Other toxicities included QTc prolongation in nine patients with CLL; myelosuppression was also observed but was more pronounced in patients with myeloma. MTD for CLL was $75 \mathrm{mg} / \mathrm{m}^{2}$, one patient demonstrating $>50 \%$ reduction in measurable disease. ${ }^{111}$

\section{Targeting the DNA Bendamustine}

Bendamustine is a traditional alkylating agent, which has emerged as an effective therapy in lymphoproliferative disorders including CLL. Bendamustine acts primarily through the formation of intra-stand and inter-stand crosslinking between DNA bases resulting in inhibition of DNA replication, repair, and transcription. Bendamustine has recently been approved for the treatment of CLL based on a randomized trial in comparison with chlorambucil. ${ }^{12}$ In the pivotal study of previously untreated CLL, patients were treated with bendamustine $(\mathrm{n}=162) 100 \mathrm{mg} / \mathrm{m}^{2}$ intravenously on days 1 and 2 every 4 weeks or chlorambucil $(n=157)$ $0.8 \mathrm{mg} / \mathrm{kg}$ orally on day 1 and 15 or as divided doses on days 1 to 2 and 15 to 16 in some cases of a 28-day cycle for a total of 6 cycles. ORR with bendamustine and chlorambucil was $68 \%$ and $31 \%(P<0.0001)$, respectively, with a $\mathrm{CR}$ of $31 \%$ and $2 \%$, respectively. Median progression free survival was 21.6 months and 8.3 months with bendamustine and chlorambucil $(P<0.0001)$, respectively. Overall the treatment with bendamustine was well tolerated except for more myelosuppression, although the rate of infectious complications was similar. ${ }^{113}$ Bendamustine in combination with rituximab has also been used for upfront treatment in CLL. Bendamustine has also been combined with other targeted therapies such as rituximab. In a phase II study, a 
total of 117 patients were recruited, and bendamsutine was given at $90 \mathrm{mg} / \mathrm{m}^{2}$ on days 1 and 2 and rituximab $375 \mathrm{mg} / \mathrm{m}^{2}$ on cycle 1 and $500 \mathrm{mg} / \mathrm{m}^{2}$ on the subsequent cycles. Treatment cycles were repeated every 28 days for a total of six cycles. ORR was $90.9 \%$ with a CR of $32.7 \% .^{114}$

\section{Summary}

Improved understanding of the biology of CLL has resulted in identification of novel therapeutic targets for tumor cells and their microenvironment. This has resulted in development of therapeutics with the ability to selectively target diseasedefining pathological processes. Exploitation of these targets has already started to demonstrate disease-modifying effects, with improvement in clinical responses as well as survival outcomes. The most robust data validating the evolving yet promising role of target specific therapies are for rituximab, for which combination chemotherapy strategies have clearly improved disease responsiveness and advantage in survival outcome of patients with CLL. Similarly, the ability to target intracellular pathways associated with drug resistance and clinical aggressive disease has rejuvenated the CLL therapeutic arena. In this context Bcl-2, CDK, and other potential intracellular targets continue to hold promise with the availability of more patient-convenient and target-specific molecules. Lastly, the recent introduction of immunomodulating agents has added another critical dimension to targeted therapeutics, with their ability to interrupt microenvironmental signals contributing to leukemic cell survival.

Thus the armamentarium of targeted treatment in CLL is growing at a steady pace with promising impact in the very near future (Tables 2, 3). While different compounds are now available to target critical oncogenic pathways, the challenge

Table 3 Investigational agents in chronic lymphocytic leukemia

\begin{tabular}{ll}
\hline Drug & Target \\
\hline AMD3100 & CXCR4 antagonist \\
Acadesine $^{\mathrm{a}}$ & Protein kinase activator \\
Bafetinib & Lyn kinases \\
Bevacizumab & VEGF \\
CAT-8015 & Anti-CD22 immunotoxin \\
CAL-101 & PI3 kinase inhibitor \\
GS-9219b & Lymphoid cells \\
PR0131921c & CD 20 \\
SCH 727965 & Cyclin dependent kinase inhibitor \\
SDX-101 & Cytotoxic \\
MEDI-538 & CD 19 \\
\hline
\end{tabular}

Notes: a5 aminoimidazole-4-carboxamide-I-beta-4-ribofuranoside; ${ }^{b}$ prodrug of nucleotide analog 9-(2- phosphonylmethoxyethyl) guanine (PMEG); 'third-generation monoclonal antibody; ${ }^{d}$ nonsteroidal anti-inflammatory drug; ${ }^{\mathrm{e} T}$ cell activation. Abbreviation: VEGF, vascular endothelial growth factor. lies in identifying the ideal target based on the molecular profile of the tumor cell, especially considering the clinical heterogeneity of CLL. Ongoing research continues to focus on optimizing therapeutic strategies based on molecular profiles of subsets of CLL patients as well as concentrating on developing combinations regimens engaging a multitargeted approach.

\section{Disclosure}

The authors declare no conflicts of interest in relation to this paper.

\section{Abbreviations}

ADCC, antibody-dependent cellular cytotoxicity; Akt, protein kinase B; AT-101, Isomer of gossypol; ATM, ataxia telengiectasia mutated; BCR, B-cell receptor; BF, bulky fludarabine; CDC, complement dependent cytotoxicity; CDK, cyclin-dependent kinase; CLL, chronic lymphocytic leukemia; CR, complete response; FA, fludarabine and alemtuzumab; FC, fludarabine and cyclophosphamide; FCR, fludarabine, cyclophosphamide, and rituximab; HSP, heat shock protein; IL, interleukin; IMiDs, immunomodulatory drugs; mAB, monoclonal antibodies; MTD, maximum tolerated dose; NHL, non-Hodgkin's lymphoma; ORR, overall response rate; PI3 $\mathrm{K}$, phosphoinositide 3-OH kinase; PR,

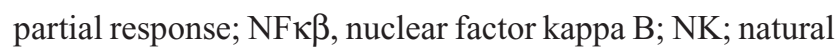
killer cells; TFR, tumor flare reaction; TNF, tumor necrosis factor; VEGF, vascular endothelial growth factor.

\section{References}

1. Morton LM, Wang SS, Devesa SS, et al. Lymphoma incidence patterns by WHO subtype in the United States, 1992-2001. Blood. 2006;107: 265-276.

2. Hallek M, Cheson BD, Catovsky D, et al. Guidelines for the diagnosis and treatment of chronic lymphocytic leukemia: a report from the International Workshop on Chronic Lymphocytic Leukemia updating the National Cancer Institute-Working Group 1996 guidelines. Blood. 2008;111:5446-5456.

3. Catovsky D, Richards S, Matutes E, et al. Assessment of fludarabine plus cyclophosphamide for patients with chronic lymphocytic leukaemia (the LRF CLL4 Trial): a randomised controlled trial. Lancet. 2007;370: 230-239.

4. Eichhorst BF, Busch R, Hopfinger G, et al. Fludarabine plus cyclophosphamide versus fludarabine alone in first-line therapy of younger patients with chronic lymphocytic leukemia. Blood. 2006;107:885-891.

5. Keating MJ, O'Brien S, Albitar M, et al. Early results of a chemoimmunotherapy regimen of fludarabine, cyclophosphamide, and rituximab as initial therapy for chronic lymphocytic leukemia. J Clin Oncol. 2005;23: 4079-4088.

6. Matutes E, Parry-Jones N, Brito-Babapulle V, et al. The leukemic presentation of mantle-cell lymphoma: disease features and prognostic factors in 58 patients. Leuk Lymphoma. 2004;45:2007-2015.

7. Kitada S, Andersen J, Akar S, et al. Expression of apoptosis-regulating proteins in chronic lymphocytic leukemia: correlations with in vitro and in vivo chemoresponses. Blood. 1998;91:3379-3389. 
8. Chiorazzi N FM: Cellular origin(s) of chronic lymphocytic leukemia: cautionary notes and additional considerations and possibilities. Blood. 2011;117:1781-1791.

9. Gorgun G, Ramsay AG, Holderried TA, et al. E(mu)-TCL1 mice represent a model for immunotherapeutic reversal of chronic lymphocytic leukemia-induced T-cell dysfunction. Proc Natl Acad Sci U S A. 2009;106:6250-6255.

10. Pleyer L, Egle A, Hartmann TN, et al. Molecular and cellular mechanisms of CLL: novel therapeutic approaches. Nat Rev Clin Oncol. 2009;6:405-418.

11. Farahani M, Treweeke AT, Toh CH, et al. Autocrine VEGF mediates the antiapoptotic effect of CD154 on CLL cells. Leukemia. 2005;19:524-530.

12. Danilov AV, Danilova OV, Klein AK, et al. Molecular pathogenesis of chronic lymphocytic leukemia. Curr Mol Med. 2006;6:665-675.

13. Caligris-Cappio F: Role of the microenvironment in chronic lymphocytic leukemia. Br J Hematol. 2003;123:380-388.

14. Chanan-Khan AA, Mavromatis B, Rai KR, et al. A pilot study of genasense (R) (oblimersen sodium, Bcl-2 antisense oligonucleotide), fludarabine and rituximab in previously treated and untreated subjects with chronic lymphocytic leukemia. ASH Annual Meeting Abstracts. 2004; 104:4827.

15. O'Brien SM, Claxton DF, Crump M, et al. Phase I study of obatoclax mesylate (GX15-070), a small molecule pan-Bcl-2 family antagonist, in patients with advanced chronic lymphocytic leukemia. Blood. 2009;113:299-305.

16. van Delft MF, Wei AH, Mason KD, et al. The BH3 mimetic ABT-737 targets selective Bcl-2 proteins and efficiently induces apoptosis via Bak/Bax if Mcl-1 is neutralized. Cancer Cell. 2006;10:389-399.

17. Brentjens RJ: Novel approaches to immunotherapy for B-cell malignancies. Curr Hematol Rep. 2005;4:64-72.

18. Ghia P, Granziero L, Chilosi M, et al. Chronic B cell malignancies and bone marrow microenvironment. Semin Cancer Biol. 2002;12:149-155.

19. Glezer E, Ferrajoli A, Reuben JM, et al. Treatment with lenalidomide (Revlimid(R)) upregulates CD40 expression on CLL Cells and increases their sensitivity to CD40-mediated cytotoxicity in vitro. ASH Annual Meeting Abstracts. 2008;112:3168.

20. Herishanu Y, Vire B, Liu D, et al. The role of the microenvironment for CLL proliferation and survival: gene expression profiling of leukemic cells derived from blood, bone marrow and lymph nodes reveals the B-cell receptor and NF \{kappa $\} \mathrm{B}$ as dominant signaling pathways. $A S H$ Annual Meeting Abstracts. 2008;112:356.

21. Osterborg A, Kipps TJ, Mayer J, et al. Ofatumumab (HuMax-CD20), a Novel CD20 monoclonal antibody, is an active treatment for patients with CLL refractory to both fludarabine and alemtuzumab or bulky fludarabine-refractory disease: Results from the planned interim analysis of an international pivotal trial. ASHAnnual Meeting Abstracts 2008; $112: 328$.

22. Chanan-Khan AA, Cheson BD. Lenalidomide for the treatment of B-cell malignancies. J Clin Oncol. 2008;26:1544-1552.

23. Chanan-Khan AA, Padmanabhan S, Miller KC, et al. In vivo evaluation of immunomodulating effects of lenalidomide (L) on tumor cell microenvironment as a possible underlying mechanism of the antitumor effects observed in patients (pts) with chronic lymphocytic leukemia (CLL). ASH Annual Meeting Abstracts. 2005;106:2975.

24. Chanan-Khan A, Miller KC, Takeshita K, et al. Results of a phase 1 clinical trial of thalidomide in combination with fludarabine as initial therapy for patients with treatment-requiring chronic lymphocytic leukemia (CLL). Blood. 2005;106:3348-3352.

25. Giannopoulos K, Dmoszynska A, Kowal M, et al. Thalidomide exerts distinct molecular antileukemic effects and combined thalidomide/fludarabine therapy is clinically effective in high-risk chronic lymphocytic leukemia. Leukemia 2009;23:1771-1778,

26. Kay NE, Shanafelt TD, Call TG, et al. N9986: a phase II trial of thalidomide in patients with relapsed chronic lymphocytic leukemia. Leuk Lymphoma. 2009;50:588-592.
27. Chanan-Khan A, Miller KC, Musial L, et al. Clinical efficacy of lenalidomide in patients with relapsed or refractory chronic lymphocytic leukemia: results of a phase II study. J Clin Oncol. 2006;24: 5343-5349.

28. Sher T, Miller KC, Lawrence D, et al. Efficacy of lenalidomide in patients with chronic lymphocytic leukemia with high-risk cytogenetics. Leuk Lymphoma. 2010;51:85-88.

29. Musial L, Miller KC, Tonelli A, et al. Low-dose prednisone decreases the severity but not the frequency of lenalidomide associated tumor flare reaction (TFR) in chronic lymphocytic leukemia (CLL) patients. ASH Annual Meeting Abstracts. 2006;108:4987.

30. Chanan-Khan A, Miller KC, Lawrence D, et al. Tumor flare reaction associated with lenalidomide treatment in patients with chronic lymphocytic leukemia predicts clinical response. Cancer. 2011;117:2127-2135.

31. Chanan-Khan AA, Czuczman MS, Padmanabhan S, et al. Clinical efficacy of lenalidomide in fludarabine-refractory chronic lymphocytic leukemia patients. ASH Annual Meeting Abstracts. 2007;110:3108.

32. Ferrajoli A, Lee BN, Schlette EJ, et al. Lenalidomide induces complete and partial remissions in patients with relapsed and refractory chronic lymphocytic leukemia. Blood. 2008;111:5291-5297.

33. Ferrajoli A, O'Brien SM, Faderl SH, et al. Lenalidomide induces complete and partial responses in patients with relapsed and treatmentrefractory chronic lymphocytic leukemia (CLL). ASH Annual Meeting Abstracts. 2006;108:305.

34. Chen C, Paul H, Xu W, et al. A phase II study of lenalidomide in previously untreated, symptomatic chronic lymphocytic leukemia (CLL). ASH Annual Meeting Abstracts. 2008;112:44.

35. Ferrajoli A, Badoux XC, O'Brien S, et al. Combination therapy with lenalidomide and rituximab in patients with relapsed chronic lymphocytic leukemia (CLL). ASH Annual Meeting Abstracts. 2009; 114:206.

36. Chen CI, Paul H, Mariela P, et al. A phase II study of lenalidomide in previously untreated, symptomatic chronic lymphocytic leukemia (CLL). ASH Annual Meeting Abstracts. 2007;110:2042.

37. Badoux X, O'Brien S, Wierda WG, et al. Combination of ofatumumab and lenalidomide in patients with relapsed chronic lymphocytic leukemia: initial results of a phase II trial. ASH Annual Meeting Abstracts. 2010;116:2464.

38. Osterborg A. Ofatumumab, a human CD20 monoclonal antibody. Expert Opin Biol Ther. 2010;10:439-449.

39. Huhn D, von Schilling C, Wilhelm M, et al. Rituximab therapy of patients with B-cell chronic lymphocytic leukemia. Blood. 2001;98: 1326-1331.

40. O'Brien SM, Kantarjian H, Thomas DA, et al. Rituximab doseescalation trial in chronic lymphocytic leukemia. J Clin Oncol. 2001;19: 2165-2170.

41. Byrd JC, Peterson BL, Morrison VA, et al. Randomized phase 2 study of fludarabine with concurrent versus sequential treatment with rituximab in symptomatic, untreated patients with B-cell chronic lymphocytic leukemia: results from Cancer and Leukemia Group B 9712 (CALGB 9712). Blood. 2003;101:6-14.

42. Wierda W, O'Brien S, Wen S, et al. Chemoimmunotherapy with fludarabine, cyclophosphamide, and rituximab for relapsed and refractory chronic lymphocytic leukemia. J Clin Oncol. 2005;23:4070-4078.

43. Tam CS, O'Brien S, Wierda W, et al. Long-term results of the fludarabine, cyclophosphamide, and rituximab regimen as initial therapy of chronic lymphocytic leukemia. Blood. 2008;112:975-980.

44. Hallek MFK, Fingerle-Rowson G, et al. Addition of rituximab to fludarabine and cyclophosphamide in patients with chronic lymphocytic leukaemia: a randomised, open-label, phase 3 trial. Lancet. 2010;376: 1164-1174.

45. O'Brien S, Osterborg A. Ofatumumab: a new CD20 monoclonal antibody therapy for B-cell chronic lymphocytic leukemia. Clin Lymphoma Myeloma Leuk. 2010;10(5):361-368.

46. Coiffier B, Lepretre S, Pedersen LM, et al. Safety and efficacy of ofatumumab, a fully human monoclonal anti-CD20 antibody, in patients with relapsed or refractory B-cell chronic lymphocytic leukemia: a phase 1-2 study. Blood. 2008;111:1094-1100. 
47. Wierda WG, Kipps TJ, Mayer J, et al. Final analysis from the international trial of single-agent ofatumumab in patients with fludarabine-refractory chronic lymphocytic leukemia. ASH Annual Meeting Abstracts. 2010; 116:921.

48. Wierda WG-KT, Mayer J, et al; Hx-CD20-406 Study Investigators. Ofatumumab as single-agent CD20 immunotherapy in fludarabinerefractory chronic lymphocytic leukemia. J Clin Oncol. 201028: 1749-1755.

49. Wierda WG, Kipps TJ, Durig J, et al. Ofatumumab combined with fludarabine and cyclophosphamide (O-FC) shows high activity in patients with previously untreated chronic lymphocytic leukemia (CLL): results from a randomized, multicenter, international, two-dose, parallel group, phase II trial. ASH Annual Meeting Abstracts. 2009;114:207.

50. Robak T. GA-101, a third-generation, humanized and glyco-engineered anti-CD20 mAb for the treatment of B-cell lymphoid malignancies. Curr Opin Investig Drugs. 2009;10:588-596.

51. Morschhauser F, Cartron G, Lamy T, et al. Phase I study of RO5072759 (GA101) in relapsed/refractory chronic lymphocytic leukemia. $A S H$ Annual Meeting Abstracts. 2009;114:884.

52. Milani C, Castillo J: Veltuzumab, an anti-CD20 mAb for the treatment of non-Hodgkin's lymphoma, chronic lymphocytic leukemia and immune thrombocytopenic purpura. Curr Opin Mol Ther. 2009;11: 200-207.

53. Morschhauser F, Leonard JP, Fayad L, et al. Humanized antiCD20 antibody, veltuzumab, in refractory/recurrent non-Hodgkin's lymphoma: phase I/II results. J Clin Oncol. 2009;27:3346-3353.

54. Goldenberg DM, Rossi EA, Stein R, et al. Properties and structurefunction relationships of veltuzumab (hA20), a humanized antiCD20 monoclonal antibody. Blood. 2009;113:1062-1070.

55. Keating MJ, Flinn I, Jain V, et al. Therapeutic role of alemtuzumab (Campath-1H) in patients who have failed fludarabine: results of a large international study. Blood. 2002;99:3554-3561.

56. Osterborg A, Dyer MJ, Bunjes D, et al. Phase II multicenter study of human CD52 antibody in previously treated chronic lymphocytic leukemia. European Study Group of CAMPATH-1H Treatment in Chronic Lymphocytic Leukemia. J Clin Oncol. 1997;15: $1567-1574$.

57. Nabhan C, Patton D, Gordon LI, et al. A pilot trial of rituximab and alemtuzumab combination therapy in patients with relapsed and/or refractory chronic lymphocytic leukemia (CLL). Leuk Lymphoma. 2004:45:2269-2273.

58. Hillmen P, Skotnicki AB, Robak T, et al. Alemtuzumab compared with chlorambucil as first-line therapy for chronic lymphocytic leukemia. J Clin Oncol. 2007;25:5616-5623.

59. Lozanski G, Heerema NA, Flinn IW, et al. Alemtuzumab is an effective therapy for chronic lymphocytic leukemia with p53 mutations and deletions. Blood. 2004;103:3278-3281.

60. Awan FT, Lapalombella R, Trotta R, et al. CD19 targeting of chronic lymphocytic leukemia with a novel $\mathrm{Fc}$-domain-engineered monoclonal antibody. Blood. 2010;115:1204-1213.

61. Furman RR, Andritsos L, Flinn IW, et al. Phase 1 dose escalation study of TRU-016, an anti-CD37 SMIPTM protein in relapsed and refractory CLL. ASH Annual Meeting Abstracts. 2010;116:56.

62. Andritsos L, Furman RR, Flinn IW, et al. A Phase 1 Trial of TRU-016, An Anti-CD37 small modular immunopharmaceutical (SMIPTM) protein in relapsed and refractory CLL: early promising clinical activity. $A S H$ Annual Meeting Abstracts. 2009;114:3424.

63. Advani R, Forero-Torres A, Furman RR, et al. Phase I study of the humanized anti-CD40 monoclonal antibody dacetuzumab in refractory or recurrent non-Hodgkin's lymphoma. J Clin Oncol. 2009;27: 4371-4377.

64. Furman RR, Forero-Torres A, Shustov A, et al. A phase I study of dacetuzumab (SGN-40, a humanized anti-CD40 monoclonal antibody) in patients with chronic lymphocytic leukemia. Leuk Lymphoma. 2010; $51: 228-235$

65. Robak T. Novel monoclonal antibodies for the treatment of chronic lymphocytic leukemia. Curr Cancer Drug Targets. 2008;8(2):156-171.
66. Woodworth J, Leigh BR, O'Brien S, et al. Pharmacokinetics of Single-Agent Lumiliximab (Anti-CD23 Antibody) in Patients with Chronic Lymphocytic Leukemia. ASH Annual Meeting Abstracts. 2004; 104:4831.

67. Byrd JC, Castro J, O'Brien S, et al. Comparison of results from a phase $1 / 2$ study of lumiliximab (Anti-CD23) in combination with FCR for patients with relapsed CLL with published FCR results. ASH Annual Meeting Abstracts. 2006;108:32.

68. Byrd JC, O'Brien S, Flinn I, et al. Safety and efficacy results from a phase I trial of single-agent lumiliximab (anti-CD23 antibody) for chronic lymphocytic leukemia. ASH Annual Meeting Abstracts. 2004; 104:2503.

69. Byrd JC, Kipps TJ, Flinn IW, et al. Phase 1/2 study of lumiliximab combined with fludarabine, cyclophosphamide, and rituximab in patients with relapsed or refractory chronic lymphocytic leukemia. Blood. 2010;115:489-495.

70. LeMaistre CF, Saleh MN, Kuzel TM, et al. Phase I trial of a ligand fusion-protein (DAB389IL-2) in lymphomas expressing the receptor for interleukin-2. Blood. 1998;91:399-405.

71. Frankel AE, Fleming DR, Powell BL, et al. DAB389IL2 (ONTAK) fusion protein therapy of chronic lymphocytic leukaemia. Expert Opin Biol Ther. 2003;3:179-186.

72. Morgan SJ, Seymour JF, Prince HM, et al. Confirmation of the activity of the interleukin-2 fusion toxin denileukin diftitox against chemorefractory chronic lymphocytic leukemia, including cases with chromosome 17p deletions and without detectable CD25 expression. Clin Cancer Res. 2004;10:3572-3575.

73. Gonzalvez F AA: New insights into apoptosis signaling by Apo2L/ TRAIL. Oncogene. 2010;29:4752-65.

74. Inoue $\mathrm{S}$, MacFarlane $\mathrm{M}$, Harper $\mathrm{N}$, et al. Histone deacetylase inhibitors potentiate TNF-related apoptosis-inducing ligand (TRAIL)-induced apoptosis in lymphoid malignancies. Cell Death Differ. 2004 (11 Suppl 2):S193-S206.

75. Plumas J, Jacob MC, Chaperot L, et al. Tumor B cells from nonHodgkin's lymphoma are resistant to CD95 (Fas/Apo-1)-mediated apoptosis. Blood. 1998;91:2875-2885.

76. MacFarlane M, Harper N, Snowden RT, et al. Mechanisms of resistance to TRAIL-induced apoptosis in primary B cell chronic lymphocytic leukaemia. Oncogene. 2002;21:6809-6818.

77. Czuczman MS, Maddipatla S, Knight J, et al. In vitro synergistic antitumor activity by targeting TRAIL-R 1 and CD 20 antigen by combining HGS-ETR1 (agonistic human monoclonal antibody to TRAIL receptor 1) and rituximab monoclonal antibody against non-Hodgkin's lymphoma cells (NHL). ASH Annual Meeting Abstracts. 2005;106:1475.

78. Ghoshal P, Chitta K, Vujcic S, et al. Mapatumumab, a TRAIL receptor 1 agonist antibody, induces apoptosis in bortezomib resistant multiple myeloma. ASH Annual Meeting Abstracts. 2009;114:2832.

79. Younes A, Vose JM, Zelenetz AD, et al. Results of a phase 2 Trial of HGS-ETR1 (agonistic human monoclonal antibody to TRAIL receptor 1) in subjects with relapsed/refractory non-Hodgkin's lymphoma (NHL). ASH Annual Meeting Abstracts. 2005;106:489.

80. Natoni A, MacFarlane M, Inoue S, et al. TRAIL signals to apoptosis in chronic lymphocytic leukaemia cells primarily through TRAIL-R1 whereas cross-linked agonistic TRAIL-R2 antibodies facilitate signalling via TRAIL-R2. Br J Haematol. 2007;139:568-577.

81. Marks PA, Richon VM, Kelly WK, et al. Histone deacetylase inhibitors: development as cancer therapy. Novartis Found Symp. 2004;259: 269-281; discussion 281-288.

82. Kaufmann SH, Steensma DP. On the TRAIL of a new therapy for leukemia. Leukemia. 2005;19:2195-21202.

83. Drummond DC, Noble CO, Kirpotin DB, et al. Clinical development of histone deacetylase inhibitors as anticancer agents. Annu Rev Pharmacol Toxicol. 2005;45:495-528.

84. Herishanu Y P-GP, Liu D et al. The lymph node microenvironment promotes B-cell receptor signaling, NF-kappaB activation, and tumor proliferation in chronic lymphocytic leukemia. Blood. 2011;117: 563-574. 
85. Friedberg JW SJ, Sweetenham J, et al. Inhibition of Syk with fostamatinib disodium has significant clinical activity in non-Hodgkin's lymphoma and chronic lymphocytic leukemia. Blood. 2010;115:2578-2585.

86. Veldurthy A, Patz M, Hagist S, et al. The kinase inhibitor dasatinib induces apoptosis in chronic lymphocytic leukemia cells in vitro with preference for a subgroup of patients with unmutated $\mathrm{IgV}_{\mathrm{H}}$ genes. Blood. 2008;112:1443-1452.

87. Amrein PC, Attar E, Takvorian T, et al. Dasatinib has activity in relapsed/refractory chronic lymphocytic leukemia (CLL/SLL), a phase II trial. ASH Annual Meeting Abstracts. 2008;112:3162.

88. Wang S, Yang D, Lippman ME: Targeting Bcl-2 and Bcl-XL with nonpeptidic small-molecule antagonists. Semin Oncol. 2003;30:133-142.

89. Letai A, Sorcinelli MD, Beard C, et al. Antiapoptotic BCL-2 is required for maintenance of a model leukemia. Cancer Cell. 2004;6:241-249.

90. Patel MP MA, Patel PS, Chanan-Khan AA. Targeting the Bcl-2. Curr Opin Oncol. 2009;21:516-523.

91. O’Brien S, Moore JO, Boyd TE, et al. 5-year survival in patients with relapsed or refractory chronic lymphocytic leukemia in a randomized, phase III trial of fludarabine plus cyclophosphamide with or without oblimersen. J Clin Oncol. 2009;27:5208-5212.

92. Nguyen M, Marcellus RC, Roulston A, et al. Small molecule obatoclax (GX15-070) antagonizes MCL-1 and overcomes MCL-1mediated resistance to apoptosis. Proc Natl Acad Sci USA. 2007;104: 19512-19517.

93. Borthakur G, O’Brien S, Ravandi-Kashani F, et al. A phase I trial of the small molecule pan-Bcl-2 family inhibitor obatoclax mesylate (GX15-070) administered by 24 hour infusion every 2 weeks to patients with myeloid malignancies and chronic lymphocytic leukemia (CLL). ASH Annual Meeting Abstracts. 2006;108:2654.

94. Balakrishnan K, Burger JA, Wierda WG, et al. AT-101 induces apoptosis in CLL B cells and overcomes stromal cell-mediated Mcl-1 induction and drug resistance. Blood. 2009;113:149-153.

95. James D, Castro JE, Loria O, Prada CE, Aguillon RA, Kipps TJ. AT-101, a small molecule Bcl-2 antagonist, in treatment naïve CLL patients (pts) with high risk features; Preliminary results from an ongoing phase I trial. J Clin Oncol. 2006;24:6605.

96. Castro JE, Olivier LJ, Robier AA, et al. A Phase II, Open Label Study of AT-101 in combination with rituximab in patients with relapsed or refractory chronic lymphocytic leukemia. ASH Annual Meeting Abstracts. 2006;108:2838.

97. Stolz C, Hess G, Hahnel PS, et al. Targeting Bcl-2 family proteins modulates the sensitivity of B-cell lymphoma to rituximab-induced apoptosis. Blood. 2008;112:3312-3321,

98. Wilson W, O'Conner O, Roberts AW, et al. ABT-263 activity in patients with relapsed or refractory lymphoid malignancies in particular chronic lymphocytic leukemia (CLL)/small lymphocytic lymphoma (SLL). J Clin Oncol. 2009;27:15s.

99. Cuni S, Perez-Aciego P, Perez-Chacon G, et al. A sustained activation of PI3 K/NF-kappaB pathway is critical for the survival of chronic lymphocytic leukemia B cells. Leukemia. 2004;18:1391-1400.

100. De Frias M, Iglesias-Serret D, Cosialls AM, et al. Akt inhibitors induce apoptosis in chronic lymphocytic leukemia cells. Haematologica. 2009; 94(12):1698-1707.
101. Herman SE, Gordon AL, Wagner AJ, et al. Phosphatidylinositol 3-kinase-delta inhibitor CAL-101 shows promising preclinical activity in chronic lymphocytic leukemia by antagonizing intrinsic and extrinsic cellular survival signals. Blood. 2010;116:2078-2088.

102. Furman RR, Byrd JC, Brown JR, et al. CAL-101, an isoform-selective inhibitor of phosphatidylinositol 3-kinase P110\{delta\}, demonstrates clinical activity and pharmacodynamic effects in patients with relapsed or refractory chronic lymphocytic leukemia. ASH Annual Meeting Abstracts. 2010;116:55.

103. O'Brien S. New agents in the treatment of CLL. Hematology Am Soc Hematol Educ Program. 2008:457-464.

104. Trepel J, Mollapour M, Giaccone G, et al. Targeting the dynamic HSP90 complex in cancer. Nat Rev Cancer. 2010;10:537-549.

105. Khalil AA, Kabapy NF, Deraz SF, Smith C. Heat shock proteins in oncology: diagnostic biomarkers or therapeutic targets? Biochim Biophys Acta. 2011;1816(2):89-104. Epub ahead of print.

106. Jones DT, Addison E, North JM, et al. Geldanamycin and herbimycin A induce apoptotic killing of B chronic lymphocytic leukemia cells and augment the cells' sensitivity to cytotoxic drugs. Blood. 2004; 103:1855-1861.

107. Lin K, Rockliffe N, Johnson GG, et al. Hsp90 inhibition has opposing effects on wild-type and mutant p53 and induces p21 expression and cytotoxicity irrespective of p53/ATM status in chronic lymphocytic leukaemia cells. Oncogene. 2008;27:2445-2455.

108. Chen R, Keating MJ, Gandhi V, et al. Transcription inhibition by flavopiridol: mechanism of chronic lymphocytic leukemia cell death. Blood. 2005;106:2513-2519.

109. Byrd JC, Lin TS, Dalton JT, et al. Flavopiridol administered using a pharmacologically derived schedule is associated with marked clinical efficacy in refractory, genetically high-risk chronic lymphocytic leukemia. Blood. 2007;109:399-404.

110. Lanasa MC, Andritsos L, Brown JR, et al. Interim analysis of EFC6663, a multicenter phase 2 study of alvocidib (flavopiridol), demonstrates clinical responses among patients with fludarabine refractory CLL. ASH Annual Meeting Abstracts. 2010;116:58.

111. Tong WG, Chen R, Plunkett W, et al. Phase I and pharmacologic study of SNS-032, a potent and selective Cdk2, 7, and 9 inhibitor, in patients with advanced chronic lymphocytic leukemia and multiple myeloma. J Clin Oncol. 2010;28(18):3015-3022.

112. Knauf WU, Lissichkov T, Aldaoud A, et al. Phase III randomized study of bendamustine compared with chlorambucil in previously untreated patients with chronic lymphocytic leukemia. J Clin Oncol. 2009;27:4378-4384.

113. Knauf WU, Lissichkov T, Aldaoud A, et al. Bendamustine versus chlorambucil in treatment-naive patients with B-cell chronic lymphocytic leukemia (B-CLL): results of an international phase III study. ASH Annual Meeting Abstracts. 2007;110:2043.

114. Fischer K, Cramer P, Stilgenbauer S, et al. Bendamustine combined with rituximab (BR) in first-line therapy of advanced CLL: a multicenter phase II trial of the German CLL Study Group (GCLLSG). ASH Annual Meeting Abstracts. 2009;114:205.
OncoTargets and Therapy

\section{Publish your work in this journal}

OncoTargets and Therapy is an international, peer-reviewed, open access journal focusing on the pathological basis of all cancers, potential targets for therapy and treatment protocols employed to improve the management of cancer patients. The journal also focuses on the impact of management programs and new therapeutic agents and protocols on

\section{Dovepress}

patient perspectives such as quality of life, adherence and satisfaction The manuscript management system is completely online and includes a very quick and fair peer-review system, which is all easy to use. Visit http://www.dovepress.com/testimonials.php to read real quotes from published authors. 